\title{
Responsabilidad del Estado derivada de la falta o falla en la protección del espacio público'.
}

\section{State responsibility derived from the lack or failure in the protection of public space.}

\author{
Autores: Jorge Mejía Turizo² \\ Rina Ropain Salas ${ }^{3}$ \\ Correspondencia: jorge.mejia@curnvirtual.edu.co ; rinaropasalas@gmail.com
}

RESUMEN

El presente artículo de reflexión tiene como propositivo axial establecer ciertos presupuestos de imputación que permitan la configuración de un nexo de causalidad entre la omisión estatal y un daño derivado de la falta o falla en la protección del espacio público. Para lo cual se ha dispuesto de un diseño metodológico con un tipo de investigación jurídico - descriptivo, un método deductivo, abordado desde un enfoque cualitativo y un paradigma histórico hermenéutico.

\section{Palabras clave:}

Responsabilidad del Estado, Falla del servicio, espacio público, daño antijurídico.

\section{ABSTRACT.}

The present article of reflection has as an axial proposal to establish certain assumptions of imputation that allow the configuration of a nexus of causality between the state omission and an injury derived from the lack or failure in the protection of public space. For which a methodological design has been provided with a type of legal - descriptive research, a deductive method, approached from a qualitative approach and a historical hermeneutical paradigm.

\footnotetext{
${ }^{1}$ El presente artículo se deriva de una sección de un proyecto denominado "presupuestos de configuración de
} los títulos de imputación en la responsabilidad extracontractual del estado" desarrollado por el investigador JORGE MEJÍA TURIZO en el grupo de investigación Andrés Bello de Corporación Universitaria Rafael Núñez, Campus Barranquilla, y que contó con el apoyo de RINA ROPAIN SALAS, quien aportó sus experiencias en El Edumas - Soledad, ente con funciones relacionadas con el espacio público. Además la Estudiante de semillero de investigación IVONNE MARTÍNEZ ANGULO contribuyó como auxiliar de investigación.

${ }^{2}$ Abogado, Magister en Derecho administrativo, Doctorando en Derecho, Ciencia política y Criminología por la Universidad de Valencia, España. Diplomado en Gestión y Públicas de la Escuela Superior de administración Pública ESAP, Docente investigador del grupo de investigación Andrés Bello de Corporación Universitaria Rafael Núñez, Campus Barranquilla, Profesor Catedrático de la Universidad del Atlántico, Ex becario del programa jóvenes investigadores e innovadores de Colciencias.

${ }^{3}$ Abogada, Magister en Derecho Administrativo, Doctorado en Ciencias Políticas de la Universidad Rafael Belloso Chacín URBE, Diplomado en Docencia Universitaria y pedagogía, Exdirectora Jurídica de Edumas Soledad y Ex asesora Jurídica del Concejo Distrital de Barranquilla. 


\section{Keywords:}

State responsibility, service failure, public space, unlawful damage.

\section{Introducción.}

Partiendo de una revisión de la literatura científica sobre el tema de la responsabilidad del Estado, puede señalarse que este tópico es abundante en la doctrina e investigaciones iuspublicistas, sin embargo si se hace una delimitación material del concepto para restringirla en exclusiva a la responsabilidad del estado por su omisión a la hora de proteger, vigilar, salvaguardar, conservar o recuperar el espacio público, en realidad en este punto concreto no es tan prolífica ni la doctrina, ni la jurisprudencia, aunque buscando aproximaciones al fenómeno es posible hallar otras situaciones que a pesar que no son directamente relacionadas con la omisión en la preservación del espacio público, si hacen referencia a la omisión, indolencia, desidia o desgreño del estado para proteger otros intereses colectivos como es el caso de la seguridad pública, el control del territorio, la explotación de recursos que en principio pertenecen a la nación. Así las cosas, se tocaran investigaciones que aunque no sean directamente relacionadas con la responsabilidad patrimonial del Estado en la preservación del espacio público, si tienen que ver con la responsabilidad estatal por perjuicios que aunque hayan sido cometidos por terceros la administración tenía la obligación jurídica de utilizar todos los medios dispuestos a su alcance para evitar su consumación.

Dicho lo anterior, se trae pues a consideración la investigaciones realizadas por Angélica Armenta Ariza (2009) relativas al régimen de la responsabilidad 
patrimonial del Estado en Colombia, más especialmente a los títulos jurídico de la imputación, en la cual señala que esos títulos jurídicos de imputación bajo los cuales está llamado a responder patrimonialmente el Estado cuando ocasiona un daño antijurídico, hoy en Colombia no obedecen a un esquema objetivo como inicialmente se quiso presentar por parte de la jurisprudencia del Consejo de Estado a partir de la expedición de la Constitución Política de 1991, sino que por el contrario, lo que esta norma constitucional consagra es que la responsabilidad del Estado sigue siendo subjetiva, por cuanto debe probarse la existencia de un daño antijurídico, el cual debe ser imputable al Estado, y esta imputación se hace mediante los llamados títulos jurídicos de imputación. Como daño especial, falla del servicio, riesgo excepcional, daño por actividades peligrosas. Con esta investigación se pretendió demostrar que, si bien se pensó que con la expedición del artículo 90 de la Constitución política de 1991 los regímenes jurídicos de responsabilidad preconstitucionales desaparecerían por cuanto la norma citada había tornado objetiva la responsabilidad patrimonial del Estado, posteriormente, el Consejo de Estado fue atenuando esta tendencia y comenzó a utilizar en cada una de sus providencias nuevamente los títulos jurídicos de imputación, los cuales se mantienen. Es decir, que hoy en día el régimen de la responsabilidad patrimonial del Estado es por regla general de tipo subjetiva, salvo algunas excepciones de responsabilidad objetiva.

Por su parte los tratadistas de la universidad del Rosario (Colombia) Mantilla Espinosa y Perdomo Parada (2002), en su investigación sobre la imputabilidad del daño en materia de responsabilidad por actividades peligrosas señalan que el régimen de responsabilidad es probablemente la disciplina jurídica que más cambios ha sufrido en las últimas décadas, en efectos, los avances tecnológicos y científicos y los nuevos riesgos que estos conllevan ha hecho aparecer insuficiente el régimen general de 
responsabilidad concebido por el legislador de los siglos XIX y XX. En efecto, en relación con el caso colombiano, partiendo del artículo 2356 del código Civil la jurisprudencia colombiana ha llegado a elaborar un régimen especial de responsabilidad que no encuentra cimentado sobre la noción de culpa y que ha permitido equilibrar los altos riesgos y los grandes beneficios que son la consecuencia de la utilización de los avances tecnológicos en la sociedad.

De igual manera, Yolanda Margaux Guerra (2010) en sus disertaciones investigativas sobre la novedosa tendencia jurisprudencial colombiana sobre responsabilidad del estado por actos terroristas, expresa que el Consejo de Estado comienza a mostrar una tendencia muy criticada en materia de declaratoria de responsabilidad del Estado por actos de terrorismo. Este artículo muestra la primera tendencia en la cual ya se está condenando al Estado, previo el lleno de unos requisitos que deben acompañar al acto terrorista. El principio general del derecho que expresa: "todo aquel que cause un daño a otro debe repararlo" permite deducir que la persona que ocasionó un perjuicio a otro incurre en una responsabilidad civil o penal y está en la obligación de resarcir el daño causado por Los funcionarios que no cumplen debidamente sus obligaciones "incurren en responsabilidad" la cual puede ser de diferente naturaleza: disciplinaria, penal, civil, política, patrimonial. En este ensayo se analizan éstas responsabilidades y sus diversas consecuencias, así como el aspecto legal de la defensa judicial del Estado.

\section{Metodología.}


El presente artículo se deriva de una investigación que se desarrolló en el marco de una la tipología jurídica - descriptiva teniendo en consideración objeto central de la investigación fue establecer presupuestos de imputación que permitan la configuración de un nexo de causalidad entre la omisión estatal y un daño derivado de la falta o falla en la protección del espacio público. El paradigma acogido fue el histórico hermenéutico y el enfoque se orientó a lo cualitativo. La técnica de recolección de información fue el análisis documental a través de unas fichas analítica - descriptiva.

\section{Resultados y discusiones.}

\section{Responsabilidad del estado y preservación del espacio público.}

En lo que respecta a la responsabilidad del Estado por la no conservación del espacio público, podría decirse que esta tiene su fundamento en el artículo 82 Constitucional, en el cual se señala que "es deber del Estado velar por la protección de la integridad del espacio público y por su destinación al uso común, el cual prevalece sobre el interés particular. Las entidades públicas participarán en la plusvalía que genere su acción urbanística y regularán la utilización del suelo y del espacio aéreo urbano en defensa del interés común".

Al respecto de espacio público, desde una posición doctrina, Belalcázar Erazo, E. A. (2011) enseña que es un derecho colectivo que confiere una potestad limitada, (por oposición al derecho de propiedad que otorga un poder total de uso y disposición, predicable tan sólo sobre bienes privados), sobre bienes de uso público; esta facultad reside en la prerrogativa de usar 
tales bienes, con arreglo a las normas legales, administrativas 0 convencionales, que prescriben su preservación y proscriben su uso exclusivo o excluyente.

Tomando en consideración estas preceptivas constitucionales podría señalarse que si el estado omite su deber de velar por la protección del espacio público y la regulación del uso del suelo, y se produce un daño, que aunque fuera producido por un particular, el Estado podría responder patrimonialmente por ser indolente frente a su función de preservar, conservar y garantizar el uso común y adecuado del espacio público. Y adicionalmente por no cumplir los parámetros relativos a los usos del suelo señalados en los planes de ordenamiento territorial y en el régimen de control urbano nacional.

Una responsabilidad de esta naturaleza intentó endilgarse al Estado en un proceso que se resolvió mediante la sentencia del veintiséis (26) de enero de dos mil once (2011) del Consejo de Estado, en la que en síntesis fáctica se relata que unas personas se encontraban comiendo en un establecimiento que se ubicaba en un sardinel al lado de una avenida principal de la ciudad de Cali, cuando súbitamente un vehículo que iba a gran velocidad se sale de la carretera, subiéndose al contiguo sardinel y provocando la muerte a una persona. El demandante señaló en ese momento que el lugar donde acaecieron los hechos es un espacio público que no puede ser utilizado por particulares para la destinación de actividades comerciales. No obstante ello, para la fecha de los hechos, aun cuando el Municipio conocía del funcionamiento del establecimiento no ejerció sus facultades de policía para recuperar el espacio público, como tampoco vigiló que dicho lugar cumpliera con el mínimo de medidas de seguridad debido a su cercanía con una vía de alta velocidad, por lo que se pidió condenar patrimonialmente al Estado. 
En esta oportunidad el Consejo de Estado señalo que el hecho dañoso por el cual se depreca la responsabilidad de la entidad demandada, ocurrió por el actuar determinante de un tercero; un menor de edad que de manera irresponsable conducía un vehículo en estado de embriaguez y a alta velocidad; en estas condiciones, mal podría imputársele al Estado la responsabilidad patrimonial, cuando la causa del hecho dañoso se produjo por el actuar determinante de un tercero. Asimismo continuando arguyendo el Honorable tribunal de cierre que aunque el demandante sostenga que existe una concurrencia de culpas, determinada por el actuar de un tercero y por la omisión por parte del Municipio de Santiago de Cali de proteger el espacio público, no obstante, tal omisión, no quedo plenamente acreditada en el proceso, si se tiene en cuenta que la parte demandante, teniendo la carga de probar la falla del servicio endilgada, no acreditó que en este caso, el Municipio conociera sobre el riesgo que representaba para la comunidad la cercanía entre la vía por la cual transitaban vehículos a alta velocidad y el espacio público que comprendía la bahía, y no hubiera adoptado las medidas necesarias para prevenir el peligro, colocando las señales de advertencia o instalando barreras para evitar la invasión de vehículos en dicho espacio, por el contrario, obra en el proceso la inspección judicial en la cual se verifica que el lugar donde se encontraban las victimas "no obstaculiza el tránsito y existe aislamiento entre el sitio donde se recibe el servicio y la vía rápida.

Es palpable pues, que en el caso relacionado el Consejo de Estado encuentra probada la configuración "del Hecho de un tercero", lo cual rompe el nexo causalidad que intento imputar el demandante por la omisión del Estado en la protección del Espacio público.

Teniendo en consideración los elementos facticos expuestos, se plantea un problema que surge al interior del fenómeno de la responsabilidad del Estado, 
consistente establecer si a pesar que exista un hecho de un tercero que genere un daño podría imputársele responsabilidad compartida al Estado por no tomar las medidas tendientes a la protección y preservación del Espacio público.

Para la materialización del espacio público el estado, puede adoptar medidas para separar los bienes destinados al espacio público de abruptos accesos de elementos invasores, que incluso pueden poner en riesgo la integridad de quienes circulen por dichos espacios públicos, en ese orden de ideas, en la Sentencia T024 de 2000, Alejandro Martínez de la Corte Constitucional, determina que en la situación específica de los "bolardos", las resoluciones procuradas por las autoridades municipales y distritales para que fueran ubicados en determinados sitios, a fin de constituir una disgregación efectiva entre la vía vehicular y la vía peatonal, y disuadir con ese obstáculo la usurpación del espacio peatonal por parte de vehículos, es una medida legítima de la autoridad local; que cumple además un objetivo viable, en bien de la comunidad, incluidos los peatones. (Citado por Belalcázar Erazo, 2011)

Para garantizar el cumplimiento efectivo a medidas dirigidas a la protección del espacio público, conforme la expresa la sentencia T 150 de 1995, el bien de uso público otorga al estado la facultad de detentar el derecho a la conservación de los mismos y por lo tanto la normatividad que los regula ordena velar por su mantenimiento, construcción y protección contra ataques de terceros o hechos negligentes de estos mismos (Gómez \& Gómez, 2003). La protección se puede realizar a través de dos alternativas: por vía administrativa, que tiene que ver con el poder de policía y por el otro lado la vía judicial, utilizando las acciones populares, acciones de grupo, y si de su falta de protección se predica un daño individual puede hacerse usos de medios de control de reparación directa.

Ahora bien, El estado posee el deber jurídico de proteger el espacio público, esta obligación incluso se ha elevado a canon constitucional, cuando en el artículo 
82 se instituye que "es deber del Estado velar por la protección de la integridad del espacio público y por su destinación al uso común, el cual prevalece sobre el interés particular. Las entidades públicas participarán en la plusvalía que genere su acción urbanística y regularán la utilización del suelo y del espacio aéreo urbano en defensa del interés común."

De igual manera, la Ley 388 de 1997 establece que las entidades territoriales deben adoptar el plan de ordenamiento Territorial en su respectivas esferas competenciales, y señala además que El ordenamiento del territorio municipal y distrital comprende un conjunto de acciones político-administrativas y de planificación física concertadas, emprendidas por los municipios o distritos y áreas metropolitanas, en ejercicio de la función pública que les compete, dentro de los límites fijados por la Constitución y las leyes, en orden a disponer de instrumentos eficientes para orientar el desarrollo del territorio bajo su jurisdicción y regular la utilización, transformación y ocupación del espacio, de acuerdo con las estrategias de desarrollo socioeconómico y en armonía con el medio ambiente y las tradiciones históricas y culturales.

El estado tiene la potestad del control, vigilancia e inspección urbanística, así lo establece claramente la ley 810 de 2003, cuando afirma que las entidades territoriales pueden declarar la existencia de una infracción urbanística, cuando observe la localización de establecimientos comerciales, industriales, institucionales y de servicios en contravención a las normas de usos del suelo, lo mismo que el encerramiento, la intervención o la ocupación temporal o permanente del espacio público con cualquier tipo de amoblamiento, instalaciones o construcciones, sin la respectiva licencia.

Se ha visto que constitucional y legalmente al Estado le compete la protección del espacio público, pero en el contexto practico y real es una de las 
responsabilidades en las que es más ostensible la desidia de la administración pública, tan arraigada es la indolencia que quienes han ocupado el espacio público abusiva o ilegítimamente tienen cierta expectativa de protección por el tiempo prolongado bajo la permisividad estatal. Ahora, si quien ocupa ilegítimamente el espacio público bajo la mirada displicente de las autoridades o sin los controles debidos, provocada un hecho dañoso, es factible pensar en unos elementos de imputación que configuren si no la responsabilidad plena del estado, si una concurrencia de culpas entre el tercero ejecutor directo del daño y la administración que por su omisión genera las condiciones para que surja tal daño.

\section{Conclusiones.}

El vacío conceptual que intenta llenarse a través de esta investigación va direccionado a encontrar un punto de conexión entre la omisión del Estado por falta o falla en la protección del espacio público y el daño que puede provocarse directa o indirectamente por la administración o por un tercero que no es vigilado, contralado o inspeccionado por la administración. Y se pretende entonces, proponer unos elementos teóricos que posibiliten cierto grado de imputación para el ente público, toda vez que ha sido recurrente en la jurisprudencia del Consejo de Estado excluirlo de total responsabilidad en eventos en que de alguna forma la administración debió velar por el correcto uso de suelo y de espacios de utilización común.

Este articulo contiene proposiciones de valor teórico y es de relevancia social teniendo en cuenta que plantea no solo elementos para evolucionar a un nuevo paradigma de responsabilidad estatal, sino que procura sentar presupuestos para una dinámica más frontal del Estado en la recuperación 
del espacio público, que a la vez concilie intereses públicos privados y prevenga eventos dañosos en los puntos urbanos de confluencia social.

Además, si existen nuevos elementos de responsabilidad en materia de protección del espacio público las distintas instituciones del estado podrían redireccionar sus políticas en asuntos de promoción del ordenamiento de su territorio, el uso equitativo y racional del suelo, la preservación y defensa del patrimonio ecológico y cultural localizado en su ámbito territorial y la prevención de desastres en asentamientos de alto riesgo, así como la ejecución de acciones urbanísticas eficientes.

Es conveniente establecer nuevos elementos de imputación de responsabilidad para el estado, que permitan que los afectados por hechos dañosos productos de la indebida utilización de los suelos logren obtener una reparación, que en la mayoría de las ocasiones no es satisfecha pues los agentes directos no se encuentran en capacidad de reparar o por poca claridad al configurar los elementos de responsabilidad en el proceso.

\section{Referencias.}

Armenta Ariza, A. (2009). El régimen de la responsabilidad patrimonial del Estado en Colombia: El título jurídico de la imputación. Revista VIA IURIS, (6), 90114. 
Vol.9, No 1. Diciembre de 2017 pp. 116-127

Belalcázar Erazo, E. A. (2011) Defensa constitucional del derecho al espacio público. Universidad Nacional de Colombia. Facultad de Derecho, Ciencias Políticas y Sociales Departamento de Derecho. Tesis de Maestría en Derecho.

Congreso de la Republica de Colombia, Ley 388 de 1997.

Congreso de la Republica de Colombia, ley 810 de 2003

Consejo de Estado de la Republica de Colombia, Sentencia del veintiséis (26) de enero de dos mil once (2011). Sección tercera, Sala contenciosa Administrativa.

Corte Constitucional Colombiana, Sentencia T-024 de 2000, M.P. Alejandro Martínez Caballero.

Corte Constitucional Colombiana, Sentencia T-150 de 1995, M.P. Alejandro Martínez Caballero.

Correa, M., Jaimes, J., Cardozo, S. \& Mantilla, C. (2013). Estrategia para la disminución de violencias en la escuela en la ciudad de Bucaramanga. Revista Justicia, 18(24), 14-24. Recuperado de http://publicaciones.unisimonbolivar.edu.co/rdigital/ojs/index.php/justicia/arti cle/viewFile/136/138 
Vol.9, No 1. Diciembre de 2017 pp. 116-127

Cárdenas, L. (2013). Prácticas de lectura y escritura en la universidad. ¿Qué y cómo leen y escriben los estudiantes de licenciaturas? Revista Amauta, 21, 139-162

Cruz, E. (2015). la Ciudadanía ECológiCa En aBya-yala/ amériCa latina. Amauta, 87-103.

Gómez Montes, J. \& Gómez Montes, M.X. (2003) Defensa del espacio público, Indemnización del perjuicio Colectivo derivado del incumplimiento de un contrato estatal. Pontificia universidad Javeriana. Facultad de Ciencias jurídicas. Departamento de derecho Público.

Guerra, Y. (2010). Novedosa tendencia jurisprudencial colombiana sobre responsabilidad del estado por actos terroristas. Prolegómenos. Derechos y Valores, XIII (25), 111-126.

Mantilla Espinosa, F., \& Perdomo Parada, H. (2002). Sobre la imputabilidad del daño en materia de responsabilidad por las actividades peligrosas. Revista Estudios Socio-Jurídicos, 4 (1), 115 - 129.

Trejos, L. (2013). Aproximación a las dinámicas del crimen organizado en la ciudad de Barranquilla. El caso del Frente José Pablo Díaz de las Autodefensas Unidas de Colombia (200-2006). Justicia, 118-134. 
Vol.9, No 1. Diciembre de 2017 pp. 116-127

Vega, H. (2015). Aspectos dogmáticos y políticos criminales de la estructura general del delito en el sistema penal colombiano. Justicia, 27, 42-72. Recuperado de http://dx.doi.org/10.17081/just.3.27.320

Yáñez, M. (2013). El desplazamiento forzado en la jurisprudencia de la Corte Constitucional colombiana (1991-2003): momento previo a la declaratoria forma del estado de cosas inconstitucional. Revista Justicia, (23), 191-218. Barranquilla: Universidad Simón Bolívar 